\title{
Factors influencing the choice to buy food products in Morocco
}

\author{
Loubna Zogaam Gharbi ${ }^{1{ }^{*}}$, Morad Guennouni $^{2}$, and Mahjoub Aouane ${ }^{1}$ \\ ${ }^{1}$ Laboratory Agroresource Biotechnology Environment and Quality, Faculty of Sciences, IbnTofail University, Kenitra, Morocco. \\ ${ }^{2}$ Laboratory of Health Sciences and Technologies, Higher Institute of Health Sciences of Settat,Faculty of Science and Technology of \\ Setta, Morocco.
}

\begin{abstract}
The article looks at the different factors that go into the subject of buying food products in Morocco. The latter, is undergoing a food transformation affecting the urban and rural environment. The recent changes in the choice of purchasing products by Moroccan citizens have created in the country a favorable framework for the development of territorial products. This is a descriptive study based on a questionnaire and conducted over a period of 2 months, subjects with a sample size of 180 respondents are randomly recruited on social networks. The results show that consumers are now interested in where they buy food, the quality of the products and the cost/quality ratio in these places. This study also states that despite the importance of product price to the consumer, quality is the factor most sought after by the consumer. This leads to an obligation on the part of consumers to industrialists to integrate food products with high nutritional values and to use ingredients that do not cause a danger to human health.
\end{abstract}

\section{Introduction}

For many years, the food industry has been faced with increasing consumer demand for quality and product safety. Past health crises, in particular the mad cow crisis, have therefore led to a loss of confidence among citizens. The most obvious example is that $\mathrm{EU}$ beef consumption fell by $25 \%$ at the end of 2000 . These incidents demonstrated the weakness of the food quality assurance system. They have also led to changes in the interventions of public authorities and private operators, who on the one hand identified production methods that minimise pathological risks, and on the other hand controlled and demonstrated their implementation by the company at the level of the production, processing and sales chain [1].

Morocco is undergoing a food transformation affecting the urban and rural environment. Urbanization, economic change and globalization are changing eating habits. The convenience of ready-to-eat foods, whether local or imported, has attracted a large portion of the population, particularly in urban areas, and these foods have become increasingly accessible and popular [2].

This subject of food purchasing is still undergoing changes to this day. The fact that consumers are becoming more cautious about the different factors at the time of purchase, the quality of food products, nutritional value, ingredients, packaging are the most sought-after parameters. For example, in Morocco, food hygiene and safety are the subject of much discussion. Moroccan manufacturers are required to control the quality of their products and to prove this control. They can turn to many self-checking methods, including HACCP methods [11].

Past research has shown that quality is a major factor in the choice of food products. [10] Of course, sensory factors also play an important role in consumer choice, since according to some research, choice is the result of a decision-making process, influenced by stimuli and regulated by consumers' personal characteristics [12].

Based on some past results, they found that the age factor of consumers influences in a very noticeable way the choice of food products, the reason that consumers do not buy the same products or services throughout their lives $[10,3]$.

Consumers are interested in the nutritional value of food products as an important criterion of quality, however, according to the latest research in 2014, people do not take into consideration when reading the ingredients on food packaging, [10] the thing that will be evaluated in this article to be able to compare at the end the results obtained with those found in previous research

Therefore, the objective of this survey is to study the purchasing attitude of food products among consumers by evaluating in parallel the factors that influence the choice of these products. Therefore, statistical analyses will be used to analyze the data obtained from our survey.

\section{Materials and methods}

The data of our study were collected in different regions of Morocco with a number of 218 subjects from the Moroccan population over a period of two months 
(October-November 2019). The questionnaire was distributed on social networks by filtering the respondents according to two factors; age: from 18 to 70 years old, and nationality: only Moroccan citizens were chosen, and of course taking into account people belonging to different socio-professional categories.

The survey questionnaire contains both closed and open-ended questions and was divided into three parts:

- First part: Information on the socio-demographic criteria of the respondents: age, level of education, socioprofessional category... ect. Examples of questions in this section are as follows: What is your age group, what is your socio-professional category, what is your financial situation, etc.?

- Second part: Define their general opinion on the Moroccan food products marketed; the availability of products, place of purchase ... ect. For example: How would you like to receive information about a commercial product, Do you prefer to buy local or foreign food products and why, what do you think about the availability of food products?

- Third part: Concerns various information on the purchasing criteria and the choice of food products that are put on the Moroccan market; the quality/cost ratio, the nutritional value of the products... ect. Sample questions: How much do you evaluate the cost/quality ratio of the agro-food products marketed in Morocco?, what are your motivations for buying them?, are you often interested in reading the ingredients of food products before consuming them?

Most of the questions on the questionnaire are nominal and ordinal in nature. Prior to conducting the main survey, the survey questionnaire was tested with a sample of 25 respondents to ensure that the questions were consistent and in line with the expected objectives.

Data entry and analysis was performed using SPSS 24 software. The tests used are: Principal Component Analysis (PCA); to study the relationship between ordinal qualitative variables, test $\chi 2$ and Correspondence Factor Analysis (CFA); to study the relationship between nominal or ordinal qualitative variables.

\section{Results and discussion}

\subsection{Factors influencing the purchasing criteria of food products}

At the level of the socio-demographic criteria of the respondents, significant results were obtained in relation to the factors influencing purchasing criteria, confirming what Perreau [3] stated regarding the choice of purchase, which depends considerably on stimulation, personal and social or psychological factors or circumstances. So, according to Figure(1), we found a correlation (table 1) between region and place of purchase of food products, since we see that people who live in big cities often choose department stores to do their shopping, something that does not exist in small towns where people prefer to buy in street markets. At the same time, statistics show that women choose to buy in street markets more than men. As well most respondents answer "medium" to "good" on the quality of food products in these places, the fact that explains consumer confidence in the products in these places, the thing that Marion [4] has already explained: the strong brand increases the brand name and attracts loyal consumers, while the strong brand name guarantees branded products.

It was also found that the higher the level of education is, the more the person chooses the places of purchase where there is a good quality of products (table 2).

And according to figure (2), we can see that in all regions people prefer to have information about a product at the point of sale.

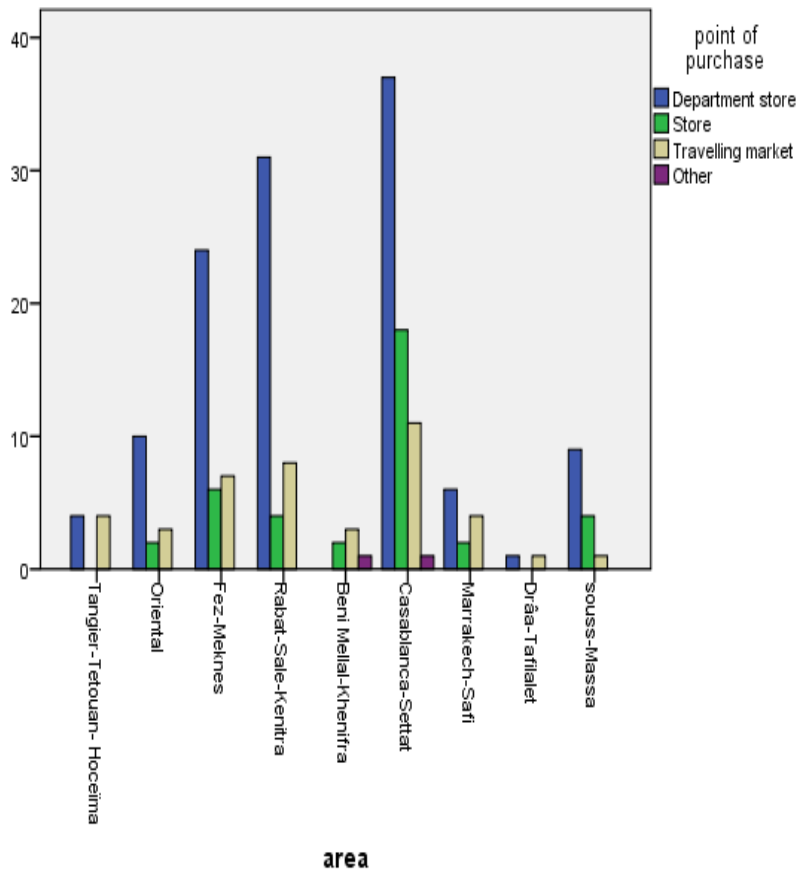

Fig. 1. Relationship between place of purchase factor and region

Table 1. Representation of the significance of the factors region and place of purchase at $(\mathrm{p}<0.05)$

\begin{tabular}{|llr|r|} 
& & Value & $\begin{array}{c}\text { Approximate } \\
\text { Significance }\end{array}$ \\
\hline Nominal by Nominal & Phi &, 442 &, 022 \\
\cline { 2 - 4 } & Cramer's V &, 255 &, 022 \\
\hline N of Valid Cases & 204 & \\
\hline
\end{tabular}

Table 2. Representation of the significance of the factors socio-professional category and place of purchase

\begin{tabular}{|llr|r|} 
& & & Approximate \\
& & Value & Significance \\
\hline Nominal by Nominal & Phi &, 632 &, 000 \\
\cline { 2 - 4 } & Cramer's V &, 365 &, 000 \\
\hline N of Valid Cases & & 201 & \\
\hline
\end{tabular}




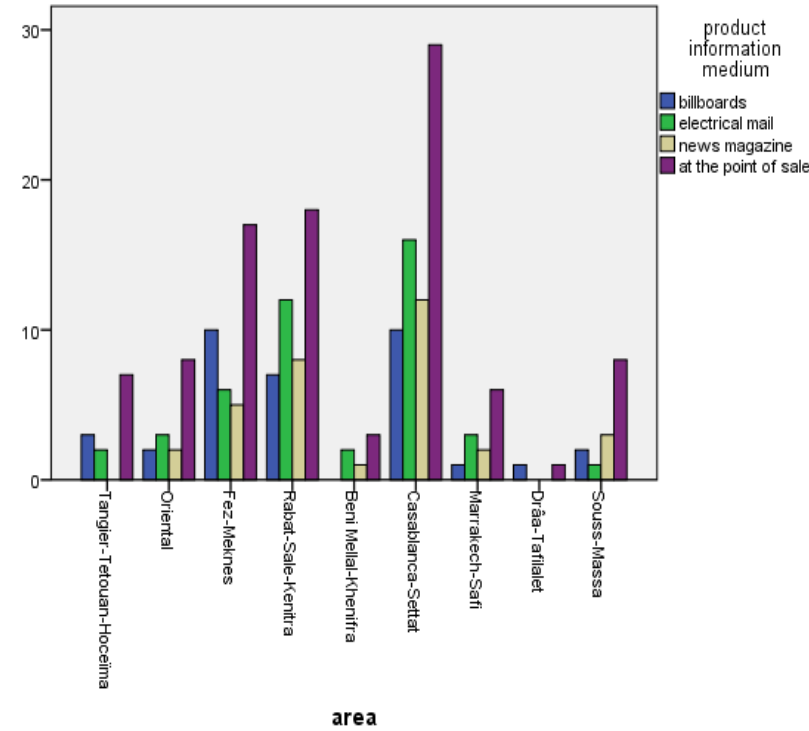

Fig. 2. Relationship between region and product information medium

Figure (3) shows that most respondents preferred to buy local products in different places of purchase, and voted "medium" to "good" in terms of the cost/quality ratio for local products more than foreign products (Figure 4). This can be explained from their answers that local food products are cheaper compared to foreign products, also because of their freshness, their availability by all and to encourage local products and economy. Our result is similar to what Hamimaz [5] announced in his article: Moroccan consumers attach great importance to the conditions of food production, their geographical origin and rural development.

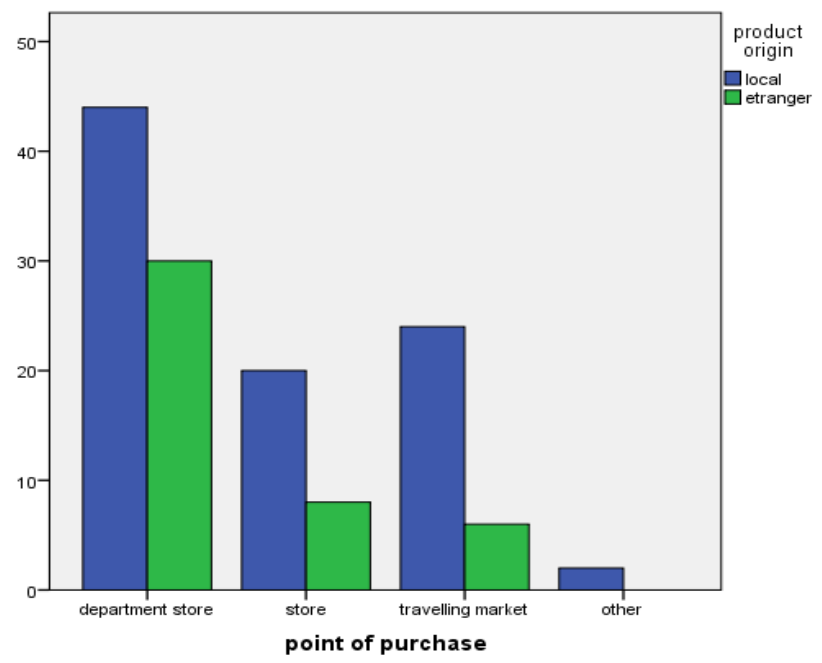

Fig. 3. Relationship between place of purchase and product origin

\subsection{Factors that influence the attitude to buying food products}

As regards the motivation for buying, $66.5 \%$ of consumers choose product quality first and $22 \%$ prefer the price at the different points of purchase, figure (5). The same reasoning was announced by Bessy and
Chateauraynaud [6] : although the search for novelty is a factor that constitutes consumer preference, the importance of learning in quality assessment cannot be ignored. As well and according to our results, we found that $69.7 \%$ of the respondents are interested in buying products that carry the "ISO certified" label.

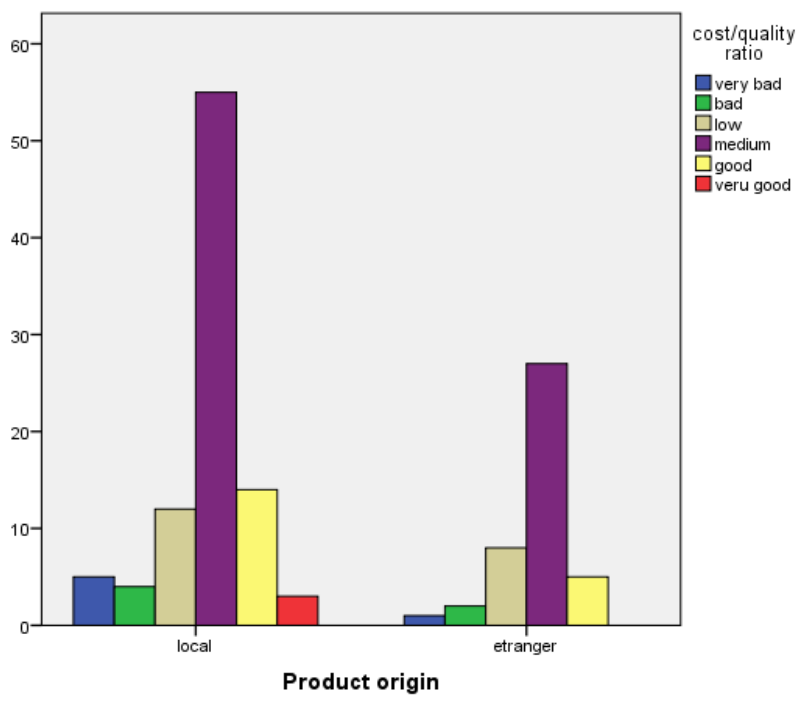

Fig. 4. Relationship between product origin and cost/quality ratio

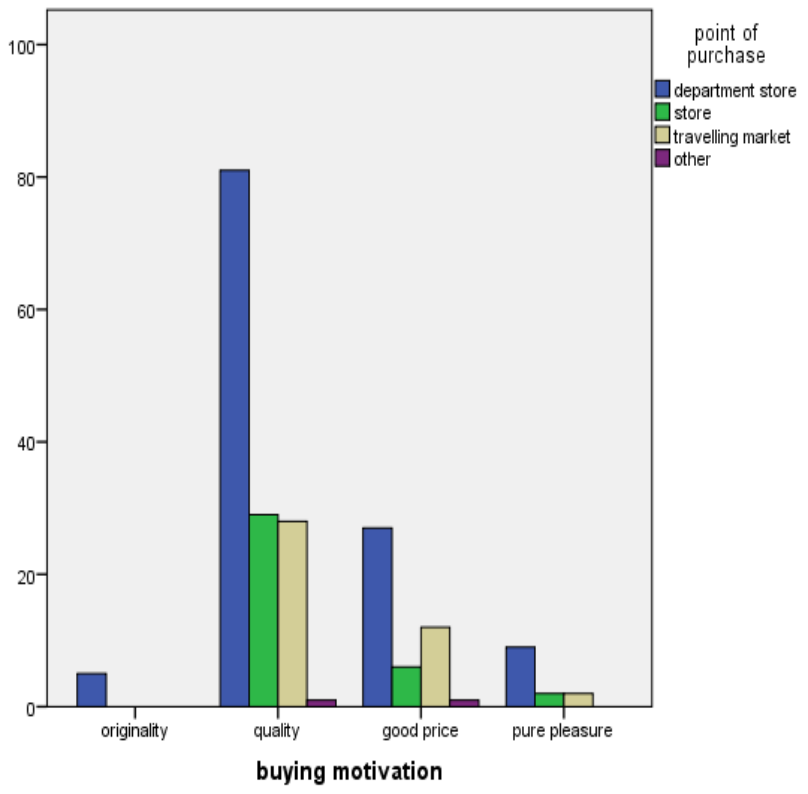

Fig. 5. Relationship between place of purchase and purchase motivation factor

It can be seen from Figure (6), that the majority of respondents are interested in reading the ingredients on the food packaging with a percentage of $56.4 \%$ of the answers by yes. So it found a strong correlation between these two factors (table 3). Figure (7) shows that the higher the level of study is, the more the respondent is interested about reading the ingredients. According to Caswell, Mojduszka, [7], cited [8]; the main purpose of nutrition labels is to inform consumers about food choices, which is also an important lever for influencing the characteristics of the food supply. 


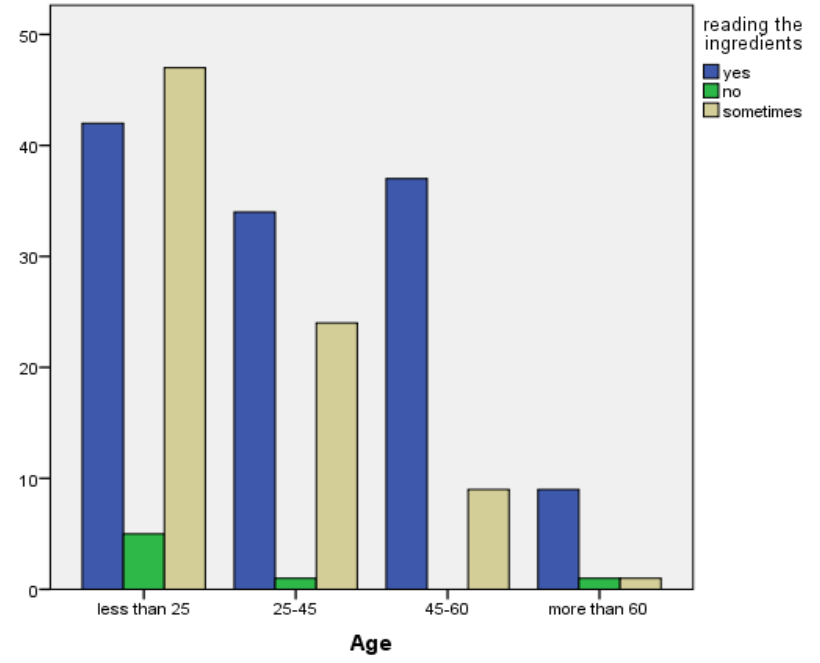

Fig. 6. Influence of Age on and ingredient reading

Table 3. Representation of the significance of the factors age and ingredient reading

\begin{tabular}{|c|c|c|c|c|c|c|}
\hline & & & Value & $\begin{array}{c}\text { Asymptotic } \\
\text { Standard } \\
\text { Error }\end{array}$ & $\begin{array}{c}\text { Approximate } \\
T^{b}\end{array}$ & $\begin{array}{l}\text { Approximate } \\
\text { Significance }\end{array}$ \\
\hline \multirow[t]{3}{*}{ Ordinal by Ordinal } & \multirow[t]{3}{*}{ Somers'd } & Symmetric & . 259 & ,057 & $-4,518$ & .000 \\
\hline & & Age Dependent & .299 & ,066 & $-4,518$ & , 000 \\
\hline & & $\begin{array}{l}\text { Ia lecture des ingredients } \\
\text { Dependent }\end{array}$ & .229 & , 050 & $-4,518$ &, 000 \\
\hline
\end{tabular}

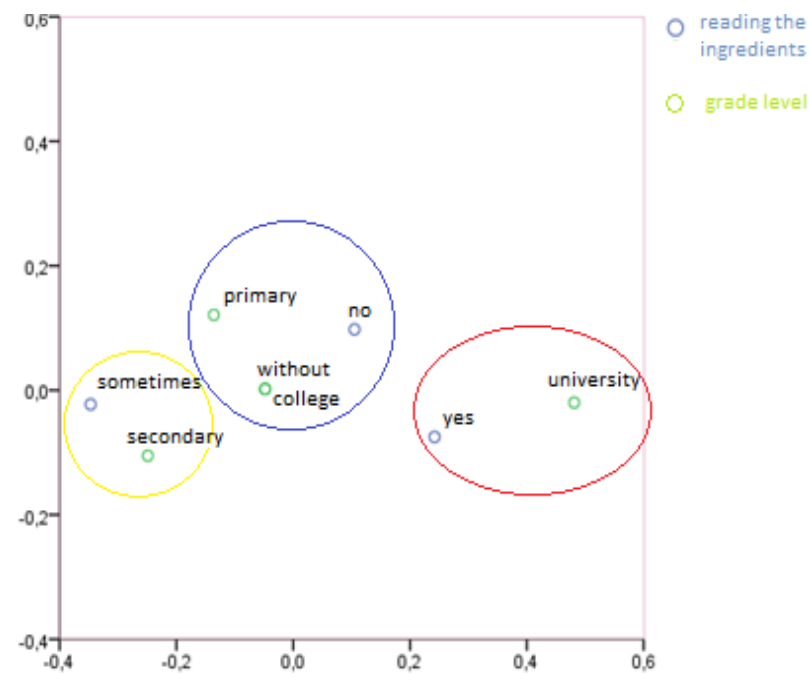

Fig. 7. Relationship between grade level and Ingredient Reading

However, according to the question asked about examples of non-conformities found in food products, most of the respondents answered by the presence of problems with food packaging, the fact that the packaging does not comply with the standards and contains only enough information about the products. This shows the importance of the shape and quality of the packaging for consumers. The same results found in the Belloute and Diouri study [10].

Among the examples of non-compliance, there is the expiry date, as respondents respond by the presence of expired food products, especially in supermarkets. The thing that states that consumers are interested in reading the validity date. Belloute and Diouri [10] also show that respondents take into consideration the reading of the expiration date, and they added that, the higher the level of study, the more systematically respondents read the validity date of products.

According to the two figures $(8,9)$, almost most respondents are interested in the nutritional value of food products, whether existing products or new products put on the market, which explains the great importance of the latter on people's health. Thus, to increase the nutritional quality of products, Combris et al, [9] have announced that there are different methods that can be used: reformulation of existing products; introduction of new products and improvements in the malnourished product categories; removing products with low nutritional levels from the market, while manufacturing new products with medium to good quality.

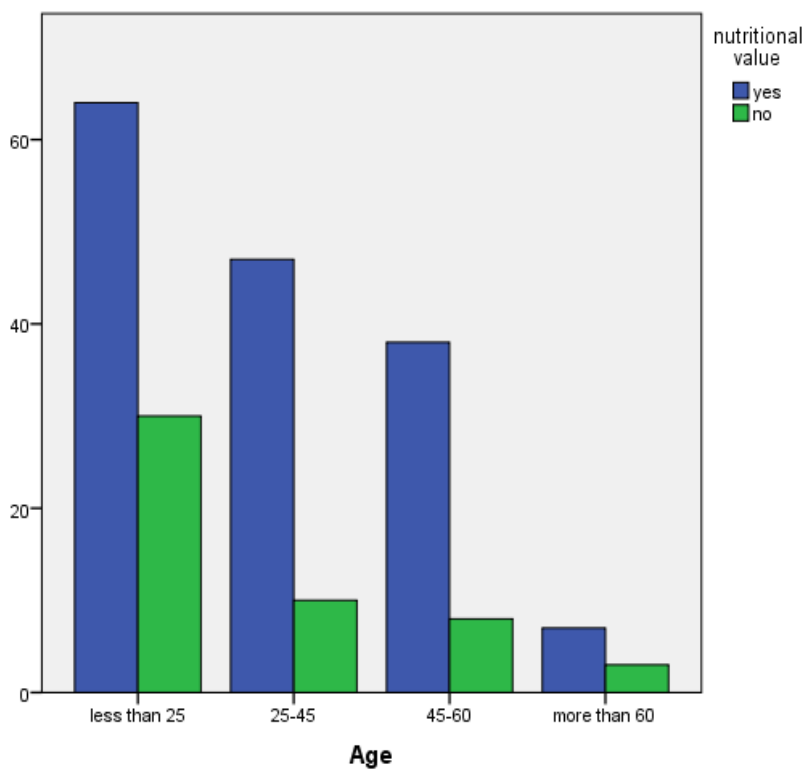

Fig. 8. The influence of age on the nutritional value of food products

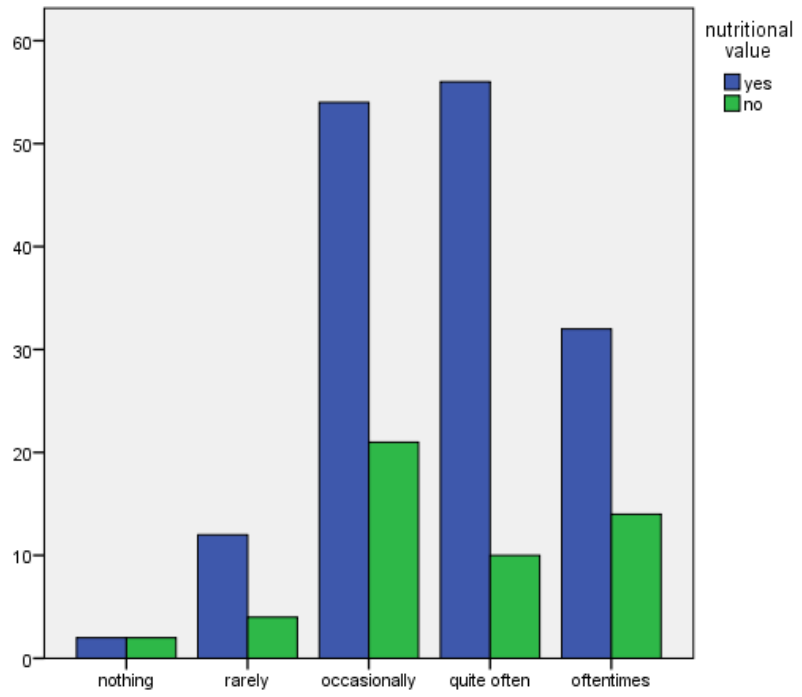

Fig. 9. Relationship between interest in new products and nutritional value 


\section{Conclusion}

It seemed important to us to explain the subject of the quality of the food products marketed in Morocco, the reason why they have been the subject for many years. Consumers today are also becoming more aware of the quality, choice and nutritional values of food products. The thing that encourages industrialists especially in the food industry to improve their products and introduce new techniques to ensure the quality of products, as well as to take an interest in the label "ISO certification". The ingredients of food products are also now the factor most controlled by consumers. This is something that according to some research was not taken into consideration before, and people do not attach much importance to information on the composition of products [10].

The limits of this research lie around the exclusion of non-Moroccan citizens residing in Morocco, and children under the age of 18. Also the absence of questions on sensory factors and quality standards used in the agri-food sector. The thing that leaves the chance to carry out other work in this direction and this time address a questionnaire to people in the field in industrial companies.

\section{References}

1. G. Fontguyon, É. Giraud-Héraud, L. Rouached, LG.Soler. The quality of produce and brand names. Sociologie du travail 45 (2003) 77-94

2. S. Benjelloun, E. Bader, M. Razès, M. C. Dop. Profil Nutritionnel du Maroc - Division de la nutrition et de la protection des consommateurs, FAO, (2011)

3. F.Perreau. Les mécanismes qui guident le comportement du consommateur. p. 1-42. (2013) Accessed 08/07/2020.

4. G. Marion, « La marque, l'enseigne et le nom de l'entreprise : Propositions pour une classification des concepts et des problématiques », Actes du $3 \mathrm{e}$ Congrès annuel de l'Association française de marketing (AFM), 6-7 mai (1987), Dinard.

5. R. Hamimaz. Le développement des produits du terroir au Maroc : quelques préalables. In: Tekelioglu Y. (ed.), Ilbert H. (ed.), Tozanli S. (ed.). Les produits de terroir, les indications géographiques et le développement local durable des pays méditerranéens. Montpellier : CIHEAM, (2009). p. 271-279 (Options Méditerranéennes : Série A. Séminaires Méditerranéens; n. 89)

6. C. Bessy, F. Chateauraynaud, «Économie de la perception et qualité des produits : L'exemple des contrefaçons dans le domaine agroalimentaire », Cahiers d'économie et sociologie rurales, $\mathrm{n}^{\circ} 37$, (1995).

7. JA. Caswell, EM. Mojduszka. Using informational labeling to influence the market for quality in food products. Am J Agric Econ (1996) ;78(5):124853.
8. JA. Caswell, Y. Ning, F. Liu, EM. Mojduszka. The impact of new labeling regulations on the use of voluntary nutrient-content and health claims by food manufacturers. J Public Policy Mark (2003); 22(2): $147-58$.

9. Pierre Combris, Géraldine Enderli; , Julie Gauvreau, Céline Ménard, Louis GeorgesSoler, Marine Spiteri, Jean-Luc Volatier. Public and private actions for improving the nutritional quality of foods: Impacts and limits. Cahiers de nutrition et de diététique (2014) 49, 22-31

10. Rachida Belloute, Mohammed Diouri. Food products purchasing criteria and behavior in morocco and their influencing factors. sciencelib editions mersenne : (2014) volume 6, $\mathrm{n}^{\circ} 141116$

11. H. Rachidi, H. Latrache. Update on microbiological quality assurance meat and meat products in Morocco. Revue d'épidémiologie et de Santé Publique (2018) RESPE-1023; No. of Pages 4

12. Filser M.1994. Le comportement du consommateur. Précis Dalloz Gestion, Paris. P. 426. Cited by Hauteville F. 2003. Processus sensoriels et préférence gustative: Apport de la recherche expérimentale au marketing agro-alimentaire. Revue française du marketing; 194 (4/5): 13-27. 